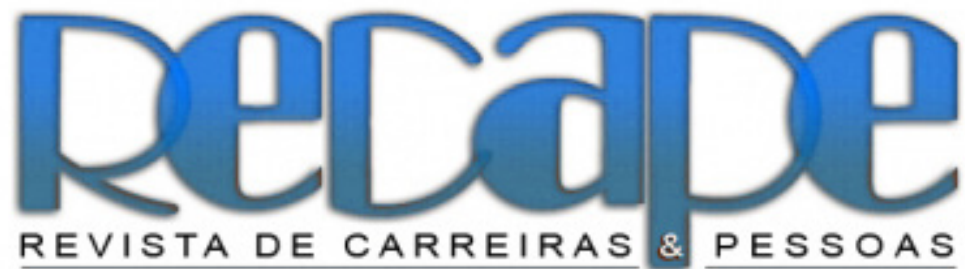

ISSN: 2237-1427

v. 11, n. 2,2021

\title{
$\mid$ \\ EDITORIAL - MULTIPLE CAREERS AND NEW SKILLS
}

The sequence of crises, financial and investment, confrontation with global production chains via criticisms of globalization, plus health with a global reach and without predictability, redefined the cycle of uncertainties surrounding the construction of careers. In this scenario, the accumulation of the most diverse work experiences represents a promising potential in organizations eager for the professional who sees, in a comfortable way, the corporate demand for multiple activities.

In this inevitable scenario of change in the work environment, with so many transformations and pressures, what set of skills has come to be the object of greater attention? What logic of diversity started to guide the specialist's "know-how" to face these difficult times? These times, in which the most different actors - inside and outside the company - define the real usefulness of each professional in corporate daily life. There is, therefore, a well-developed perception that careers, in this turbulent scenario, need to have more than one meaning, more than one direction. And, in this direction, new competences need to be assimilated.

In this context, in view of the demand for so many variables, the complex process that involves the relationship between multiple careers and new skills has become the thematic axis of the articles that make up the second issue of Volume 11 of the Revista de Carreira e Pessoas

The article that opens this edition of $\mathrm{ReCaPe}$, "Slash phenomenon: mapping professional trajectories of contemporary workers" by Eduardo Carneiro Lima, a researcher at the State University of Ceará and professors Ana Cristina Batista dos Santos, from the same institution and Patrícia Passos Sampaio, from the University from Fortaleza, aims to understand, in an interdisciplinary perspective, the generation of professionals who accumulate and practice "multiple activities", understood as slashers. The research, with a qualitative profile, used a cartographic method to map different professional trajectories. 
The proposal was both to understand who advances professionally in different knowledge territories, in a constant situation of new experiences, and to compare this choice with the linear trajectory of the more traditional career. The result of the research was the mapping of possible professional paths, with five distinct routes: that of dissatisfaction; demobilization; that of "turning around"; that of experimentation and, finally, the route of identity processes. The mapping of these routes generated two "syntheses" of analyzes. The first, the possible "glamorization" of this dynamic, with all its risks, and the second, with a more reflective proposition, explores what the "place in the world" of these workers is in constant search for new experiences.

The starting point of the second article of this edition of $\mathrm{ReCaPe}$ is that "organizations no longer represent the main environment for career development" as proposed in the text "Female careers: a systematic review on professional trajectories" by researchers Ananda Silveira Bacelar and Alyce Cardoso Campos, both from the Federal University of Lavras and from professors Monica Carvalho Alves Cappele, Flaviana Andrade de Pádua Carvalho and Daniel Carvalho Rezende, coordinator of the Postgraduate Program in Administration, all from the Federal University of Lavras. The objective of the article is to map which careers developed by women have been less addressed by studies in Administration, with the proposal to synthesize the changes that have occurred and occur in the world of work and in the professional and personal lives of individuals.

It is in this context of complex changes in career structures that women have been gaining increasing space in the labor market since the mid-1970s with increasing attention from researchers. The article has carried out a systematic review of the production since this period, analyzing the Web of Science and Scopus databases. The results obtained, in a sample of 102 articles, demonstrate that, since the 1970s, the growth of interest in the theme has been concentrated in 2015, 2016 and 2017 with seven publications per year and, in 2018 with 10 articles, the year with more publications. The qualitative result of the thematic interest reveals the concentration of this production of change in women's careers in the areas of management and the public sector.

The third article in this edition, "Occupational stress in the context of independent auditors' work", by researchers Sarah Maria Rodrigues de Vilhena and Joel Isaac Guimarães Muniz from the Federal University of Ceará, professor Juliana Vieira Corrêa Carneiro and professors Graduate Program in Administration and Accounting José Carlos Lázaro da Silva Filho and Diego de Queiroz Machado, all professors at the Federal University of Ceará, identified that the diverse demands and pressures of the routine characteristic of the "modern lifestyle" can cause different biopsychosocial consequences due to stress. With this starting point, adopting quantitative survey type research, the article investigated different characteristics of occupational stress in the typical occupations of the independent auditors' career. The notion of stress included organizations' search for excellent results, pressure for results and the very demand in an increasingly demanding and overloaded labor market, 
which drives constant criticism in relation to the performance and efficiency of their tasks. The research result identified a significant predominance of individuals in the "stress resistance" phase, with the highest number of symptoms in professionals at the beginning of their careers.

The role of social networks in consolidating changes in the work environment is the theme of the fourth article in this edition of ReCaPe with the text "Virtual social networks and their influence on recruitment and selection processes" by researcher Francine Souza Silva from Universidade Federal de Pelotas and Professor Francielle Molon da Silva of this institution and professor in the Postgraduate Program in Administration at the Federal University of Rio Grande. The objective of the article is to understand how virtual social networks, managed by the candidates themselves, influence recruitment and selection processes. And, in this way, how these same networks end up shaping work environments and career expectations. With a quantitative profile, the survey results showed that respondents were "familiar" with these virtual tools and used them not only to share experiences, but also professional contacts and "opinions". The study revealed that participants know that the target of the recruiter's search is especially the candidate's career path and are aware that networks influence the "decision-making process" in different corporate spheres

The fifth article in this edition, "Skills development for a successful career", by Professor André Luís Janzkovski Cardoso, Professor of Master in Management and Environmental Technology at the Federal University of Mato Grosso - University Campus of Rondonópolis, aims to identify, first , the perception of the competence development of graduates from the Administration course at a federal university, considering demographic variables and, also, assessing the understanding of Management professors regarding "actions and practices". The results of the study identified seven categories related to the perception of students and teachers: knowledge acquisition, career, administrator challenges, skills development, internship, theory and practice, and protagonism. These results also showed statistically significant differences on skills development involving gender, "mother's education" and "being working during graduation".

Does the possibility of multiple careers also occur in the public sector? The sixth article in this edition of ReCaPe "Stability in the Brazilian public sector: what public servants think", by professor Kamila Pagel de Oliveira from João Pinheiro Foundation and researchers Maria Thereza Mota Sampaio de Paula, Maria Thereza Mota Sampaio de Paula, Kimberly Ohana Freitas Andrade and Éder Rocha Coura, all also from the João Pinheiro Foundation, aim to evaluate the perception of public servants in a public institution on the stability and possibilities of career flexibility. In a quantitative case study format, the study discusses the efficiency of government action based on the possibility that stability generates a lack of incentive and motivation for public servants in the search for better organizational results. The quantitative profile allowed for consistent comparative observation: in the 60 to 69 age group, $60.00 \%$ are favorable to stability for all permanent positions, with only $20.00 \%$ not 
being favorable. On the other hand, in the 20 to 29 age group, 33.33\% of respondents are in favor of stability for all positions, while $22.22 \%$ are not. This result deserves crossing with the answer regarding the main factor that led them to enter the public service, $34.71 \%$ stated that it was the interest in a specific career, while stability was the main attraction for $26.45 \%$. One of the conclusions of the article suggests that there is a favorable environment for career flexibility in the public sector, based mainly on new performance evaluation formats.

In the process of building multiple careers, what is the role of corporate leaders? The seventh text of this edition, "Sustainable leadership from the perspective of human resources professionals from companies in Rio Grande do Sul" by researchers Lucas de Oliveira Maia, Karoline Konrath, from Feevale University and professor Cristiane Froehlich from the Post-Graduate Program Graduated in Business Administration from Universidade Feevale, it aims to verify the "perspective" with which human resources professionals agree and practice the concept of "sustainable leadership". The starting point of the research is that this concept is associated with another "style" of leadership that involves another format for organizational benefits, such as increased productivity, increased employee motivation and improved corporate image, where leading means shaping the culture and the organization's practices to strengthen the image before the community. The results of the research, with a quantitative and qualitative profile, demonstrate, first, that professionals in the area of human resources still need to know the concept of sustainable leadership, since only $28 \%$ knew or read about it. However, these results also show that these professionals recognized that it was necessary to insert the perspective of sustainable leadership both in the strategic and in the organization's culture.

The article that closes this edition of ReCaPe, "Labor as a means and not as an end - interrelationships between labor, personal and consumer values" by Professor Silmara Gomes, from the Centro Universitário SENAC - São Paulo, is part of the definition of values such as "desirable goals" that motivate actions, such as the concept that values" guide people's attitudes and behavior". However, he observes that this "guide" offered by the values works in a general way, but for specific issues, as the work there is "another value structure". In this way, the research aims to verify if the differences between Personal and Labor Values generate individual conflicts, which can help in explaining, even, consumption actions. With a quantitative profile, with 523 validated questionnaires, the results of the research showed that personal and work values "are related through diffusion, that is, that what is important as Personal Value contaminates the Labor Value", with conflicting relationships of proximity and between them, according to the proposed situation.

Good reading!

Leonardo Trevisan, Elza Veloso and Joel Dutra

Publishers 